\title{
TECNOLOGIAS ASSISTIVAS: O FAZER PEDAGÓGICO DE UMA PROFESSORA DA SALA DE RECURSOS MULTIFUNCIONAL
}

\author{
ASSISTIVE TECHNOLOGIES: THE TEACHER'S PEDAGOGICAL PRACTICE OF THE \\ MULTIFUNCTIONAL RESOURCE ROOM
}

\section{TECNOLOGÍAS ASISTENTES: LA PRÁCTICA PEDAGÓGICA DE UNA PROFESORA DE LA SALA DE RECURSOS MULTIFUNCIONALES}

\author{
Romilda Silva Prazeres ${ }^{1}$ \\ Verônica de Oliveira Magalhães ${ }^{2}$
}

\begin{abstract}
RESUMO
A nascente do conceito de Tecnologia Assistiva adotado no Brasil tem permitido várias interpretações sobre o que se configura, ou não, como pertencente a esta área do conhecimento. Durante pesquisa de mestrado, que visava compreender o fazer pedagógico de uma professora da Sala de Recursos Multifuncionais, tendo como base em seus atendimentos o uso da tecnologia assistiva, procuramos compreender, a partir do discurso da professora, quais são as suas concepções a respeito do conceito de Tecnologia Assistiva e Atendimento Educacional Especializado. Assim, este artigo, objetiva analisar como as estratégias pedagógicas do professor da sala multifuncional, a partir do uso das tecnologias assistivas, contribui no processo de ensino do público alvo da educação especial. Participou da pesquisa uma professora lotada na Sala de Recursos Multifuncionais onde realiza o atendimento educacional especializado. A coleta de dados se deu por meio de aplicação de questionário aberto, e as informações obtidas como respostas foram organizadas e categorizadas para análise. Os resultados
\end{abstract}

Submetido em: 01/03/2020 - Aceito em: 21/04/2020 - Publicado em: 29/04/2020

${ }^{1}$ Possui graduação em História pela Universidade Federal de Roraima (2005). Especialização em Pedagogia escolar pela FACINTER e Especialização em educação infantil pela UFRR. Atualmente exerce a função professora do Centro de Apoio Pedagógico para atendimento às pessoas com deficiência visual do estado de Roraima. Experiência em docência na área de História em escolas da Rede estadual de ensino com alunos do ensino médio.

${ }^{2}$ Mestranda do Programa de Pós-graduação Mestrado Acadêmico em Educação, da Universidade Estadual de Roraima - UERR, Especialista em Gestão do trabalho pedagógico: Administração, orientação e supervisão escolar pela Faculdade Internacional de Curitiba - FACINTER e licenciada em Normal Superior pelo Instituto Superior de Educação de Roraima - ISE/RR. Atua como professora efetiva da Secretaria de Educação, Cultura e Desportos de Roraima desde 1988, onde já desenvolveu também as funções de assessoria técnico-pedagógica e coordenadora pedagógica escolar. Desenvolve atividades de formação continuada no Centro de Formação dos Profissionais da Educação de Roraima - CEFORR/SEED/RR. Tem experiência na área de Educação, com ênfase em métodos e técnicas de ensino, atuando principalmente nos seguintes temas: alfabetização, ensino em séries iniciais, gestão pedagógica. 


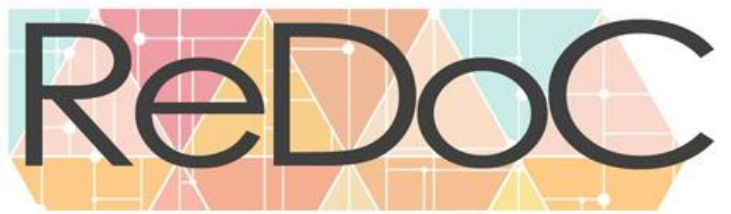

\section{Revista Docência e Cibercultura}

demonstram, por meio da pesquisa colaborativa, que são muitas as contribuições que as tecnologias assistivas trazem para a educação inclusiva. Porém verificou-se também, dentre outros, a fragilidade em relação ao conceito e sua utilização no que se refere ao atendimento aos alunos com deficiência. Entende-se que para alguns estudantes a utilização da tecnologia assistiva tornou-se uma das formas mais adequadas de ter acesso ao conhecimento, no intuito de ampliar suas habilidades e cooperar nos seus estudos, na sua comunicação e na interação com o outro.

PALAVRAS-CHAVE: Educação Especial. Prática Pedagógica. Atendimento Educacional Especializado. Tecnologias Assistivas.

\section{ABSTRACT}

The origin of the concept of Assistive Technology adopted in Brazil has allowed several interpretations concerning or not, to this area of knowledge. During a master's research, which objective was to understand the teacher's pedagogical practice of the Multifunctional Resource Room, based on her attendance the use of Assistive Technology, we tried to understand, from the teacher's discourse, what are her conceptions about the concept of Assistive Technology and Specialized Educational Services. Thus, this article aims to analyze how the pedagogical strategies of the multifunctional classroom teacher, based on the use of assistive technologies, contributes towards teaching process of the special education target audience. A teacher that works in the Multifunctional Resource Room where she performs specialized educational service participated in the research. Data collection was performed through the application of an open questionnaire, and the information obtained as answers were organized and categorized for analysis. The results demonstrate, through collaborative research, that there are many contributions that assistive technologies bring to inclusive education. However, it was also verified, among others, the fragility in relation to the concept and its use regarding the assistance to students with disabilities. It is understood that for some of them, the use of assistive technology has become one of the most appropriate ways to gain access to knowledge in order to broaden their skills and cooperate in their studies, communication and interaction with others.

KEYWORDS: Special Education. Pedagogical Practice. Specialized Educational Service. Assistive Technologies.

\section{RESUMEN}

El origen del concepto de Tecnología de Asistencia adoptado en Brasil ha permitido varias interpretaciones sobre lo que pertenece, o no, a esta área de conocimiento. Durante una investigación de maestría, que tenía como objetivo comprender la práctica pedagógica de una maestra de la Sala de Recursos Multifuncionales, en función de su asistencia al uso de tecnología de asistencia, tratamos de entender, desde el discurso de la maestra, cuáles son sus concepciones sobre el concepto de Tecnología de asistencia y servicios educativos especializados. Por lo tanto, este artículo tiene como objetivo analizar cómo las estrategias pedagógicas del maestro de aula multifuncional, basadas en el uso de tecnologías de asistencia, contribuye en el proceso de enseñanza del publico destinatario de la educación especial. Participó en la investigación una profesora de la Sala de Recursos Multifuncionales donde realiza el servicio educativo especializado. La recolección de datos se realizó mediante la aplicación de un cuestionario abierto, y la información obtenida como respuestas se organizó y clasificó para su análisis. Los resultados demuestran, a través de la investigación colaborativa, que hay muchas contribuciones que las tecnologías de asistencia hacen a la educación inclusiva. Sin embargo, también se verificó, entre otros, la fragilidad en relación con el concepto y su uso en relación con la asistencia a estudiantes con discapacidad. Se entiende que, para algunos estudiantes, el uso de tecnología de asistencia se ha convertido en una de las formas más apropiadas de obtener acceso al conocimiento para ampliar sus habilidades y cooperar en sus estudios, comunicación e interacción con los demás.

PALABRAS ClAVE: Educación Especial. Práctica Pedagógica. Servicio Educativo Especializado. Tecnología de Asistencia. 


\section{INTRODUÇÃO}

Com avanços na área educativa muitos progressos são proporcionados às Pessoas com Deficiência $(\mathrm{PcD})$, pincipalmente no que concerne a qualidade do modo em que vivem. Com o intuito de assegurar o acesso ao ensino de forma igualitária o Decreto $n^{\text {o }}$ 5.296/2004 é um documento oficial que norteia o uso de infraestrutura mobiliária e pedagógica que atenda às necessidades individuais dos estudantes. A Tecnologia Assistiva (TA) é um recurso que viabiliza de forma inovadora o alcance da informação, visto que o Atendimento Educacional Especializado (AEE), através da Sala de Recursos Multifuncionais (SRM), estimula nos estudantes suas capacidades práticas, intelectuais e estreita a concepção de independência e inclusão como uma nova forma de perceber estas pessoas. Com isso, a TA é um instrumento necessário ao se considerar o modo de acessibilidade ao conhecimento.

Estudos importantes vêm sendo realizados nesta área, BERSCH e MACHADO (2012) trazem em suas pesquisas debates sobre as abordagens das tecnologias assistivas no processo educacional e significativas considerações sobre como os professores ponderam os caminhos trilhados por seus alunos ao redirecionar novas ideias em relação ao ensino e aprendizagem. Compreender a conceituação de Tecnologia Assistiva e sua aproximação com os conhecimentos dos alunos é abordado pelos pesquisadores de maneira a esclarecer os diversos aspectos e complexidades que o tema sugere. Assim, as discussões sobre as tecnologias assistivas são ampliadas em meio a professores e estudantes da temática.

GALVÃO FILHO (2012) destaca as muitas contribuições em relação ao professor e o aluno dentro de um cenário inclusivo de uma sala de aula, dando ênfase a utilização da tecnologia assistiva que, por sua vez, vem proporcionar essa inclusão presente em situações rotineiras dentro da escola, afirmando assim que a Tecnologia Assistiva é utilizada para ampliar ou possibilitar a execução de uma atividade necessária e pretendida por uma pessoa com deficiência. Na perspectiva da educação inclusiva, esta Tecnologia é voltada a favorecer a participação do aluno com deficiência nas diversas atividades da rotina escolar, vinculadas aos objetivos educacionais. Dessa forma o autor apresenta reflexões acerca das questões que envolvem o tema como um suporte eficaz na construção de uma aprendizagem mais sólida. Aponta também, a vontade de se fazer cumprir aspectos garantidos em lei e que quase sempre não são efetivadas na realidade. Com isso, o autor colabora com os debates sobre as indagações no tocante a inclusão, reveladas na pesquisa após a análise dos dados levantados.

As questões pertinentes à inclusão são discutidas nas pesquisas de SANCHEZ (2005) quando apresenta dados referentes à relação da filosofia da inclusão e a educação eficaz para todos. Enfoca a urgência de uma investigação sobre os processos de aprendizagem do aluno e 
direciona para o uso das tecnologias assistivas como uma possibilidade de ampliar as discussões que colocam professor e aluno como centro do processo educativo. As demandas apresentadas pela autora corroboram na pesquisa com grande relevância ao abordar situações que se assemelham com as práticas vividas no dia a dia da escola.

No presente artigo foi analisado como as estratégias pedagógicas do docente que atua na Sala de Recursos Multifuncionais, considerando o uso da TA, contribuem com o processo de ensino de alunos na educação inclusiva, no ensino fundamental. Sendo os recursos de fundamental importância para se alcançar os objetivos propostos em sala de aula, pode-se destacar, no âmbito da educação especial, como Tecnologias Assistivas utilizadas na escola: os materiais escolares e pedagógicos acessíveis, a comunicação alternativa, os recursos de acessibilidade ao computador, os recursos para mobilidade, localização, a sinalização, o mobiliário que atenda às necessidades posturais, entre outros.

A pesquisa é descritiva de forma que pretende propiciar maior proximidade do tema de investigação com as discussões pedagógicas entre os pares, centra-se no estudo de caso com possibilidades de análise do contexto e obtenção de dados específicos, assim a observação do objeto de estudo pode ocorrer de maneira minuciosa com considerações relevantes para o trabalho. Os instrumentos utilizados na coleta de dados foram a observação participante em uma Sala de Recursos Multifuncionais e a aplicação de questionário aberto com o professor que atua neste espaço.

Nesta perspectiva acredita-se que a pesquisa poderá contribuir para expandir o debate sobre as possibilidades de aprendizagem e autonomia das pessoas com deficiência, considerando as propostas de políticas públicas inclusivas. Dessa maneira, este artigo se justifica por colaborar com a disseminação do uso das tecnologias assistivas como recurso para inclusão e espera-se ajudar de alguma forma na melhoria da prática dos profissionais envolvidos na formação de pessoas com deficiência.

\section{ESPAÇOS NA ESCOLA: ATENDIMENTO EDUCACIONAL ESPECIALIZADO E A SALA DE RECURSO MULTIFUNCIONAL}

Nas escolas públicas o Atendimento Educacional Especializado (AEE) é efetivado em espaços físicos nomeados como Salas de Recursos Multifuncionais (SRM). As SRM devem ser munidas com equipamentos e mobiliários adequados, materiais pedagógicos e didáticos conforme as necessidades dos alunos, acessibilidade, entre outras condições que objetivam assistir aos estudantes que necessitam deste atendimento no horário oposto a sala de aula. 


\section{Revista Docência e Cibercultura}

Estas salas estão sob a responsabilidade dos gestores escolares e professores que atuam no serviço educacional sendo garantida a organização e a administração do espaço por profissionais aptos ao exercício da docência com formação específica na área.

Conforme as Diretrizes da Política Nacional de Educação Especial o AEE nas escolas tem o intuito de verificar, executar e estruturar os instrumentos pedagógicos que serão essenciais para a definição de ações educativas inclusivas e ainda, que proporcionem a participação de todos os alunos observando suas características específicas (BRASIL, 2008). Neste atendimento todas as abordagens devem ser singulares e diferenciadas do ensino escolar regular, sem configurar como reforço ou complemento das atividades escolares. Pode sim, ser o apoio para atividades diversificadas onde podem ser estimuladas e aperfeiçoadas a prática do ensino da Língua Brasileira de Sinais (LIBRAS), o código BRAILLE, a introdução e o estímulo ao aluno para a utilização da Tecnologia Assistiva como um elo facilitador na aprendizagem.

Portanto, no AEE professor e aluno devem juntos enfrentar as dificuldades encontradas diante das circunstâncias educacionais comuns, ultrapassando os limites impostos a sua aprendizagem. Ao identificar barreiras e/ ou habilidades do aluno para o avanço na aprendizagem o docente poderá organizar o planejamento partindo do conhecimento prévio da realidade do aluno na busca de ampliar suas possibilidades de participação e desenvolvimento de atividades. Assim, a SRM é o espaço mais apropriado, porém, não o único para que estes estudantes possam utilizar todos os recursos disponíveis para a aprendizagem, inclusive tendo a TA como incentivo para a expansão da sua independência.

\section{TECNOLOGIAS ASSISTIVAS: RECURSOS DE APOIO AO PROFESSOR}

O Comitê de Ajudas Técnicas (CAT) define Tecnologia Assistiva como um campo do conhecimento que tem características interdisciplinares e envolvem recursos, metodologias, produtos, serviços, estratégias e práticas que visam uma promoção funcional quanto às formas de participação e atividades ofertadas àqueles que têm a mobilidade reduzida ou alguma deficiência, numa perspectiva de melhorar sua condição na sociedade (BRASIL, 2007). O uso da Tecnologia Assistiva como suporte ao processo inclusivo pretende tornar mais real os direitos do cidadão à educação, ainda que, mesmo com questões deficitárias, estes estejam amparados pela Política Nacional de Educação Especial na Perspectiva da Educação Inclusiva. Contudo o Decreto n ${ }^{\circ}$ 5.296/04 ao ser instituído estabelece diretrizes ao 


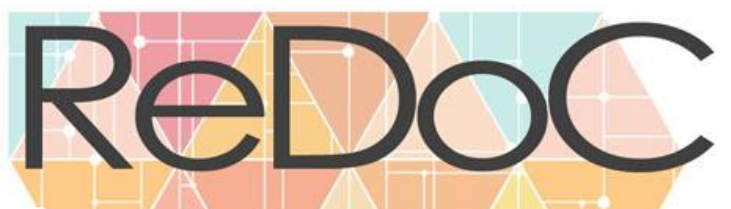

\section{Revista Docência e Cibercultura}

CAT para promoção de ações que visem dar maior transparência, aperfeiçoamento e legitimidade no que tange a TA no Brasil.

A TA é composta de instrumentos e utilidades e ao se falar sobre instrumentos, trata-se da utilização pelo aluno de equipamentos, que permite o desempenho de uma tarefa e buscam resolver os problemas funcionais do espaço na escola, criando alternativas para sua atuação e participação no que compete aos afazeres pedagógicos. No que corresponde à legislação nacional pode-se mencionar o Decreto 3.298/99 no seu artigo 19 que trata do direito do cidadão com deficiência às Ajudas Técnicas, considerando os elementos que permitem compensar uma ou mais limitações funcionais motoras, sensoriais ou intelectuais da PcD, visando permitir-lhe superar as barreiras da comunicação e da mobilidade e de possibilitar sua plena inclusão social (BRASIL, 1999). Assim, nesta intencionalidade há inúmeros recursos que facilitam incluir os estudantes e que devem estar adequados de acordo com suas características particulares.

Este novo padrão inclusivo fortalece o AEE como condição fundamental para o estudante com deficiência, matriculado em classe regular, de maneira que ele adquira condições apropriadas e acessíveis ao currículo. Conforme Galvão Filho (2012) a TA propicia sustentação para consolidar um novo modelo inclusivo, tanto na escola como na sociedade de forma que envolva totalmente a todos, minimizando os preconceitos na prática e nos discursos elaborados sobre e pela pessoa com deficiência. Assim, existem inúmeras possibilidades de utilização de instrumentos simples e de baixo custo, que podem ser ofertados nos espaços escolares segundo a emergência de cada estudante.

Sendo a escola um espaço propício a manifestação da diversidade humana, cabe as pessoas envolvidas frente ao desafio da educação ser verdadeiramente inclusiva. Percebe-se no campo da pesquisa que a realização de debates e discussões com relação ao assunto em questão são realizados constantemente, bem como várias formas de atendimento educacional especializado ao aluno que necessita do serviço. A professora responsável pela SRM na escola e que realiza diretamente com o AEE apresenta características e desenvolve atribuições de um profissional atuante que estabelece estratégias pontuais para obtenção de resultados significativos.

Pensar práticas pedagógicas com amplitudes diversificadas para alunos público alvo da educação especial na escola, é uma tarefa bem complexa. $\mathrm{O}$ fazer pedagógico da professora em questão é estruturado com ações diárias, semanais e mensais através de um plano de atendimento que estabelece como os estudantes serão atendidos. Desta forma, a professora vincula o atendimento à proposta pedagógica da escola que propicia a inclusão com ações concretas em busca de alcançar a aprendizagem de todos. Dentre as atividades listadas pela 
profissional da SRM em seu plano de ações, está também a formação continuada dos demais professores da escola, a fim de criar um espaço formativo em que possam ser realizados estudos teóricos e a socialização de experiências educacionais entre si, como forma de contribuir para a evolução dos conhecimentos na coletividade. O estímulo à produção de recursos de acessibilidade também é uma das ações pedagógicas atribuídas a SRM, são as tecnologias assistivas e as ajudas técnicas. Para isso, é realizado uma parceria com o professor da sala regular a fim de adequar o currículo, descrever o número de atendimentos, que acontecem extensivamente, durante todo o ano, e como eles irão acontecer.

\section{PROCEDIMENTOS METODOLÓGICOS}

A investigação proposta está fundamentada numa abordagem qualitativa, pois como trata Severino (2007, p.119) esta designação diz respeito à "[...] um conjunto de metodologias, envolvendo, eventualmente diversas referências epistemológicas". Descritiva no que se refere aos objetivos, a pesquisa busca a interpretação dos dados coletados através de questionário aberto, pois, “[...] o sujeito pode elaborar as respostas, com suas próprias palavras, a partir de sua elaboração pessoal" (SEVERINO 2007, p.126). Assim as informações levantadas junto ao participante da pesquisa, retratam através da escrita, sua opinião sobre o assunto em estudo.

A pesquisa trata-se de um estudo de caso desenvolvido no âmbito de uma escola pública estadual, de ensino fundamental e médio, localizada na zona oeste do município de Boa Vista - RR. O critério de escolha da instituição de ensino foi o fato de ter sido o local onde realizouse pesquisa de campo para atender o cumprimento de disciplinas obrigatórias do mestrado em educação. Também foi neste ambiente que foi estreitado o contato com a professora da SRM e alunos com atendimento educacional especializado. Para as análises e conclusões, foram observados os trabalhos realizados pela professora que acompanha as atividades pedagógicas dos alunos incluídos nas salas comuns das turmas de $6^{\circ}$ ao $9^{\circ}$ ano, por 50 horas, distribuídas em 4 semanas.

Ao retomar o objetivo da pesquisa que visa analisar como as estratégias pedagógicas do professor da sala multifuncional, a partir do uso das tecnologias assistivas, contribui no processo de ensino do público alvo da educação especial, é importante ressaltar as considerações de Mantoan (2006) que afirma que as mudanças nas práticas dos professores depende que estes estejam conscientes do que se pretende propiciar para alunos, escola e o sistema de ensino, assim como o seu desenvolvimento profissional. Com isso, presume-se que 
o trabalho da professora participante da pesquisa, vá além do conhecimento teórico e seja o facilitador no processo pedagógico ao mediar o ensino do professor e a aprendizagem do aluno, pois é necessário identificar as necessidades destes para desenvolver uma ação colaborativa.

Para reunir as informações necessárias utilizou-se a observação participante na SRM e um questionário aberto, com cinco (5) perguntas, aplicado no intuito de obter dados sobre como as estratégias pedagógicas da professora que atua neste espaço, considera o uso das tecnologias assistivas de forma a contribuir com o processo de ensino e aprendizagem na educação especial. Diante das práticas pedagógicas desenvolvidas dentro das classes, a utilização das Tecnologias Assistivas como instrumento que pretende ser um fator atenuante no processo inclusivo devem ser subsídios de ensino para o professor da Sala de Recursos Multifuncionais e uma forma de incentivo para o professor da sala regular na utilização destas tecnologias em suas aulas.

\section{ANÁLISE E DISCUSSÃO DOS DADOS}

Os dados relativos aos aspectos do pensamento crítico da professora participante da pesquisa foram obtidos mediante conversas diárias e a aplicação de questionário aberto. Para um tratamento dos dados de forma objetiva e sem o risco de erros, utilizou-se como estratégia a análise da fala a partir da interação do pesquisador e da participante da pesquisa e os fatos registrados nas respostas do questionário. Foram construídas percepções, significados e interpretações dos dados obtidos considerando as formas a partir das quais o pesquisado produziu sentido ao 'que' e 'como' relata e se posiciona em relação aos fatos levantados.

A pesquisa teve como norte as respostas dadas pela professora da SRM a cinco (5) questões propostas. Ao analisar a fala da professora participante da pesquisa nota-se que, no que se refere a como as salas multifuncionais estão sendo utilizadas pelos docentes e alunos no Ensino Fundamental, é relatado que no ano de 2019 poucos professores da sala regular, e até mesmo professores auxiliares ${ }^{3}$, solicitaram orientações quanto aos procedimentos didáticos para dar apoio aos alunos. Aponta que somente em situações esporádicas é requerida a assistência do professor da sala de recursos e que "[...] apenas um professor da sala regular

\footnotetext{
${ }^{3}$ Professor auxiliar é o profissional licenciado que realiza atendimento especializado, em consonância com a Lei de Diretrizes e Bases da Educação Nacional (LDB), que estabelece no Artigo 58, § $1^{\circ}$ que, "haverá, quando necessário, serviços de apoio especializado, na escola regular, para atender às peculiaridades da clientela de educação especial”.
} 
solicitou ajuda quanto à aplicação de uma prova para um aluno com necessidade educacional especial, e um professor auxiliar, solicitou orientações de como proceder com um aluno autista [...]". Evidencia assim, a fragilidade na utilização da Sala de Recursos Multifuncionais.

Ao considerar a baixa procura para o atendimento na Sala de Recursos Multifuncionais da escola, destaca-se que o profissional desta sala tem como atribuição estabelecer uma articulação com o professor da classe comum (MENDES, 2006), mas ao se dá essa aproximação deve-se observar e considerar aos fatores que influenciam ou influenciaram a pouca procura aos atendimentos ofertados. No campo da pesquisa, o que pode ser observado, através da fala da professora, é que os motivos são diversos, porém há que se destacar o mais frequente na vivência dos professores desta comunidade escolar: a condição de ter mais tempo para orientação aos professores da classe regular, uma vez que a rotina do cronograma das aulas, carga horária e retorno para estudos, mesmo sendo realizado quinzenalmente, o tempo destinado as questões referentes a e Educação Especial é mínimo.

A Educação Especial propicia a complementação e suplementação da formação do aluno com deficiência, sendo imprescindível que haja uma articulação dos sujeitos envolvidos na ação de ensino, ou seja, o professor da sala regular e o professor da Sala de Recursos Multifuncionais. Nesta perspectiva deve-se considerar o currículo e as finalidades preteridas, de forma que a construção do conhecimento do aluno com deficiência seja proposta mediante um trabalho em conjunto. Neste aspecto, Correia (1999) destaca que

[...] a noção da escola é um espaço educativo aberto, diversificado e individualizado, em que cada criança possa encontrar respostas a sua individualidade, à sua diferença. A integração pressupõe assim a utilização máxima dos aspectos mais favoráveis do meio para o desenvolvimento total de sua personalidade (CORREIA, 1999, p.19).

$\mathrm{Na}$ escola campo da pesquisa, durante a observação, percebeu-se que o atendimento dos alunos na SRM, acontece posterior ao horário normal das aulas e é realizada semanalmente de modo a propiciar a ampliação da aprendizagem dos alunos, de forma individualizada e com duração de duas horas. Percebe-se o desenvolvimento deste Atendimento quando a professora responde aos questionamentos de como este é realizado e se os alunos fazem uso das tecnologias assistivas disponíveis na sala de recursos. A professora descreve que: "[...] elas são sim utilizadas e são de fundamental importância para a melhor compreensão das temáticas/ assuntos trabalhados e possibilita um melhor desenvolvimento das aprendizagens [...]". Assim, nesses Atendimentos a TA contribui significativamente com a aprendizagem do aluno e favorece um estímulo no desenvolvimento das atividades curriculares. 
Neste sentido, espera-se que o docente da SRM, dentre outras atribuições, explore e saiba não apenas empregar os recursos disponíveis, mas adequá-los ao uso dos discentes e que possa gerenciar esses materiais no ambiente da sala regular. Galvão Filho (2009) evidencia que a TA dentro do contexto educacional, é o elo para viabilizar novos horizontes dentro do processo de ensino e aprendizagem estimulando o progresso intelectual de alunos de forma que seja possível alcançar os objetivos necessários à sua aprendizagem. Vale destacar que, a TA na escola, desde que seja bem utilizada, possibilita a efetiva inclusão do aluno com destaque às suas potencialidades, estímulo e motivação para a construção de conhecimentos.

O destaque do uso das tecnologias assistivas ficou evidenciado quando em seu discurso a professora responde a seguinte questão: Diante das práticas pedagógicas desenvolvidas dentro das salas, qual a importância da utilização das tecnologias assistivas nas atividades inclusivas na escola? A esta indagação ela se posiciona: "[...] é necessário utilizar metodologias e recursos que possibilitem ao educando essa maior liberdade no ato de aprender [...]" e explicita também que a utilização das tecnologias assistivas "[...] suscita nos alunos a potencialização de suas habilidades funcionais, tornando as atividades escolares, como outras, mais possíveis e mais fáceis [...]". Percebe-se, na fala da professora, o quanto a TA é importante para a vida dos indivíduos, não se apresentando de forma diferente àqueles que carecem de atendimento especializado.

Quando se trata de TA, na escola, está se colocando em discussão algumas alternativas para a superação, para avistar novas possibilidades e modos de enfrentamento das dificuldades que possam surgir em cada ambiente. É proposto um trabalho com a inovação, com a criação de formas concretas para minimizar as barreiras causadas pela deficiência e disponibilidade de recursos de acessibilidade e ainda, favorecer ao aluno oportunidades para a aprendizagem e desenvolvimento de forma ampla (BERSCH e MACHADO, 2012). No entanto, mesmo que seja imputada à escola a obrigação de dispor de recursos e métodos para incluir os discentes, nem todas dispõem de recursos materiais e humanos para isso. Assim, destaca-se a necessidade de ofertar novas possibilidades de desenvolver suas habilidades através das tecnologias assistivas.

Ainda nesta perspectiva, no ambiente escolar pesquisado, questionou-se a professora: Quais as contribuições que a TA traz para o processo de inclusão na escola? Em sua resposta ela aponta a importância do uso das tecnologias assistivas no ensino e aprendizagem do aluno e as contribuições que trazem para a educação inclusiva, assim como destaca também que são aspectos que favorecem a "[...] autonomia na aprendizagem e 'independência' na construção do conhecimento [...]”. Para tanto, Bersch e Machado (2012) enfatizam que as novas ideias para a construção do conhecimento exigem uma nova forma de pensar e reorganizar o currículo, traz uma reflexão sobre as responsabilidades de seus atores principais, os 
professores e os alunos. Portanto, estes contribuem diretamente com a expansão do processo educativo que envolve a escola e seus partícipes, todos numa única ação.

$\mathrm{Na}$ escola campo da pesquisa, segundo a estruturação e organização do atendimento da SRM é proposto parcerias com todos os professores para dinamizar o processo de inclusão do aluno no sistema escolar. Ao levantar a questão: De que forma são propostas estratégias de ensino para o professor, de modo que o incentive na utilização das tecnologias assistivas em suas aulas? Nota-se que os docentes não demonstram interesse em trocar informações, no intuito de auxiliar no desenvolvimento da aprendizagem do aluno. Isto fica evidente na fala da professora que revela: “[...] infelizmente, no momento ainda não há solidificada essa parceria entre professor da Sala Multifuncional e professor da sala regular, Inclusive estou com um projeto de intervenção na escola que visa justamente criar esse 'laço pedagógico', através da fomentação do que é a Educação Especial na escola". Considera-se assim, que ao menos existe a intenção voltada para a mudança da realidade local.

Com base nas respostas obtidas e analisadas nas abordagens teóricas, é possível constatar que a relação dos professores com a Sala de Recursos Multifuncionais está em processo de construção. Uma vez que há a tentativa do docente que atua nesta sala em realizar o trabalho de maneira sistemática, percebe-se a necessidade de uma organização do trabalho pedagógico que atenda a todos os estudantes semanalmente e que seja estreitada a relação com os professores. As Tecnologias Assistivas vêm sendo utilizadas e implementadas na escola, e mesmo que seja um processo lento, sua inserção nos trabalhos com os professores tem se mostrado alvo de esclarecimento de dúvidas, exposições de opiniões, inquietações e ansiedade em relação ao tema. Destaca-se que o trabalho desenvolvido pela professora da SRM tem apontado para um caminho satisfatório de estruturação das atividades dentro da escola e as contribuições da TA apresenta-se como questões teóricas e metodológicas necessárias ao grupo de docentes e alunos.

\section{CONSIDERAÇÕES FINAIS}

As atividades pedagógicas da professora da SRM, diante do que foi exposto, contribuem de forma significativa com a integração, inclusão e aprendizagem dos alunos que necessitam de Atendimento Educacional Especializado, visto que nesta perspectiva a atuação dos professores e o uso da TA é muito relevante ao complementar a aprendizagem do aluno e possibilitar o desenvolvimento de sua independência e autonomia em aspectos gerais. É necessário que as ações da escola sejam repensadas e flexibilizadas para que realmente a 


\section{Revista Docência e Cibercultura}

inclusão aconteça. As ações que levam em conta os diversos ritmos de aprendizagem e o respeito na singularidade de cada um devem ser fomentadas de maneira contundente. A Constituição Federal no Artigo $5^{\circ}$ garante o princípio de igualdade ratificando que todos são iguais perante a Lei, sem distinção de qualquer natureza (BRASIL, 1988), assim, os professores poderão usufruir de novas perspectivas de trabalho com a TA propiciando o ensino e a aprendizagem na perspectiva de favorecer melhorias à vida escolar dos estudantes.

O objetivo desta pesquisa foi o de estabelecer um diálogo entre as práticas que envolvem os procedimentos relacionados ao Atendimento Educacional Especializado realizado conjuntamente com todos os envolvidos da escola para assegurar a assistência adequada aos alunos com deficiência, de modo que as estratégias pedagógicas do professor que atua na sala multifuncional, a partir do uso das tecnologias assistivas, possam contribuir efetivamente no desenvolvimento do ensino e da aprendizagem considerando os aspectos da educação inclusiva. Nesta perspectiva o trabalho realizado está em processo de (re) construção e mesmo as pequenas manifestações de ações articuladas são vitais para estabelecer o "laço pedagógico" e o estímulo no emprego de metodologias que envolvam as Tecnologias Assistivas.

Castro, Souza e Santos (2011, p. 147) assinalam que "[...] percebemos que, em sentido amplo, a evolução tecnológica caminha na direção de facilitar a vida, seja dentro ou fora do ambiente escolar [...]", consequentemente, a TA é uma ferramenta que facilita a aprendizagem considerando o ponto de partida do aluno, pois podem propiciar a evolução de habilidades e potencialidades na busca de superação dos limites impostos diariamente. A escola, como um ambiente de construção do conhecimento formal, cultural e de cidadania deve sempre conceber as possibilidades de resolução dos entraves que possam surgir e agir de forma que a inclusão aconteça com responsabilidade e respeito às diferenças na busca de conscientização de toda comunidade escolar envolvida.

Os resultados desta pesquisa permitem considerar que a articulação desenvolvida entre as partes implicadas, mesmo que num processo inicial de fortalecimento dos elos que os unam, estão no caminho da busca por uma sistematização mais efetiva e que objetiva o alvo do processo, a aprendizagem significativa do aluno. Segundo Sanchez (2005, p.10) “[...] a educação inclusiva é antes de tudo uma questão de direitos humanos [...]", neste processo, cabe ressaltar que, as pessoas da escola que estão direta ou indiretamente ligados ao aluno, necessitam estabelecer parâmetros para criar as condições necessárias de aprendizagem. Contudo, é necessário que as mudanças também ocorram na sociedade para que se torne realmente acessível e inclusivo de forma que proporcione funcionalidade e participação. 
Em síntese, a educação inclusiva tem seus limites e desafios constatados pelas mais diferentes formas, dependendo do contexto do ambiente escolar em que é realizada. Há muito que ser conquistado e assegurado, principalmente quando se refere a fragilidades da inclusão escolar na garantia de um trabalho colaborativo e de trabalho pedagógico desenvolvido pelos professores, uma vez que uma parte dos alunos atendidos por estas salas, conforme o depoimento dos professores, não têm suas necessidades plenamente atendidas. Portanto, é óbvio que há obstáculos a serem superados: a espera pela busca do atendimento, a falta disponibilidade de alguns professores, o domínio de aspectos pedagógicos específicos, entre outras situações que acontecem. Porém, na escola pesquisada existe um fator primordial existente, a motivação, sendo que, esta deve sempre ser o primeiro passo.

\section{REFERÊNCIAS}

BRANDÃO, Carlos Rodrigues. O que é educação. São Paulo: Brasiliense, 2007. (Coleção primeiros passos; 20).

BRASIL. Comitê de Ajudas Técnicas. Secretaria Especial dos Direitos Humanos da Presidência da República (CORDE/SEDH/PR), 2007a. Disponível em: <http://www.mj.gov.br/sedh/ct/corde/dpdh/corde/Comitê\%20de\%20Ajudas\%20Técnicas/Ata _VII_Reunião_do_Comite_de_Ajudas_Técnicas.doc. Acesso em: 20 nov. 2019.

BRASIL. Constituição da República Federativa do Brasil. Brasília: Senado Federal, 1988.

BRASIL. Diretrizes Operacionais da Educação Especial para o Atendimento Educacional Especializado na Educação Básica. Secretaria da Educação Básica SEEB/Ministério da Educação/MEC. Brasília: 2008.

BERSCH, Rita; MACHADO, Rosângela. Tecnologia Assistiva - TA: Aplicações na Educação/ Módulo III. Santa Maria, 2012.

CASTRO, Antonilma Santos de Almeida; SOUZA, Lucimêre Rodrigues de; SANTOS, Marilda Carneiro. Proposições teóricas para a inclusão da Tecnologia assistiva (TA) no currículo Escolar da educação básica. Sitientibus, Feira de Santana, n. 44, p. 145-158, jan./jun. 2011.

CORREIA, Luís de Miranda. Alunos com Necessidades Educacionais Especiais nas Classes Regulares. 1. ed. Portugal: Porto Editora, 1999.

BRASIL. Decreto ${ }^{\circ}$ 3.298, de 20 de dezembro de 1999. Regulamenta a Lei $n^{\circ} 7.853$, de 24 de outubro de 1989, dispõe sobre a política nacional para a integração da pessoa portadora de 
deficiência, consolida as normas e dá outras providências. Diário Oficial da República Federativa do Brasil, Brasília, DF, 21 dez. 1999.

GALVÃO FILHO, Teófilo Alves. A. Tecnologia Assistiva: de que se trata? In: MACHADO, G. J. C.; SOBRAL, M. N. (Orgs.). Conexões: educação, comunicação, inclusão e interculturalidade. Porto Alegre: Redes Editora, 2009.

GALVÃO FILHO, Teófilo Alves; MIRANDA, Teresinha Guimarães. G. Tecnologia Assistiva e salas de recursos: análise crítica de um modelo. In: GALVÃO FILHO, T. A. (Org.); MIRANDA, T. G. (Org.). O professor e a educação inclusiva: formação, práticas e lugares. Salvador: Editora da Universidade Federal da Bahia - EDUFBA, 2012, p. 247-266. ISBN: 9788523210144.

MANTOAN, Maria Teresa Égler; PRIETO, Rosângela Gavioli. (Orgs,). Inclusão escolar: pontos e contrapontos. São Paulo: Summus, 2006.

MENDES, E.G. A radicalização do debate sobre inclusão escolar no Brasil. Revista Brasileira de Educação, Campinas, v. 11, n. 33, p. 387-405, 2006.

SANCHEZ, Pilar Arnaiz. A Educação Inclusiva: um meio de construir escolas para todos no século XXI. Revista da Educação Especial. Ano I, nº 1. Out/2005.

SEVERINO, Antônio Joaquim. Metodologia do Trabalho Científico. $23^{a}$ ed. São Paulo: Cortez, 2007. 